Journal of Business \& Management (COES\&RJ-JBM)

ISSN (E): 2306-7179 ISSN (P): 2306-8043

Publisher: Centre of Excellence for Scientific \& Research Journalism, COES\&RJ LLC

Online Publication Date \& Issue: $1^{\text {st }}$ April 2016, Vol.4, No.2, April 2016

http://centreofexcellence.net/J/JBM/JBM\%20Mainpage.htm

\title{
The impact of globalization on the management of human resources in the Algerian economic enterprise
}

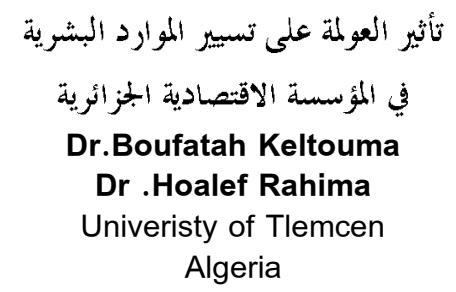

\begin{abstract}
:
The remarkable changes, including globalization way to influence the situation of economic institutions and the thought of management and administration, resulting in the emergence of an administrative model developed after the development of human capital at the top of concerns and thus integrate the strategies in the enterprise and the world economy is now working to be more interactive and more global; where most of the products now reflect all international borders and barriers, to invade world markets, but they include the resources of all kinds of raw materials and capital and manufactured goods and services such as insurance and communication systems and individuals.
\end{abstract}

\section{Keywords:}

Globalization, transformations, model governance, strategy, management of human resources, economic institution.

\section{Citation:}

Keltouma, Dr. Boufatah; Rahima, Dr. Hoalef (2016); the impact of globalization on the management of human resources in the Algerian economic enterprise; Journal of Business \& Management (COES\&RJ-JBM) Vol.4, No.2, pp.60-71. 


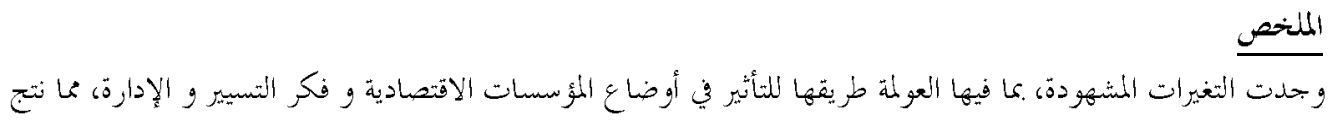

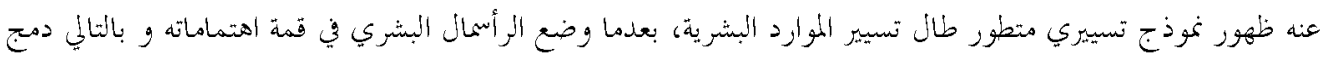

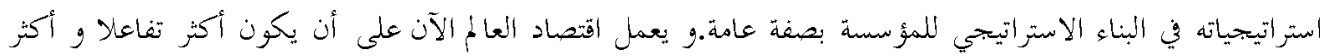

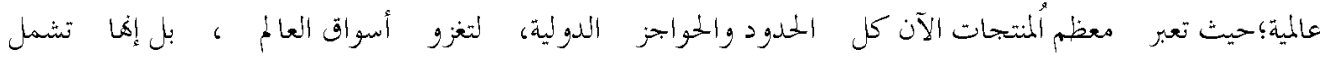

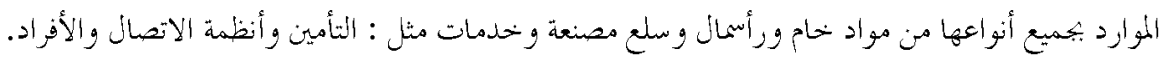
الكلمات المفتاحية : العولمة، التحولات، نموذج تسييري، إستراتيجية، تسيير الموارد البشرية، المؤسسة الاقتصادية.

عرف المقدمة:

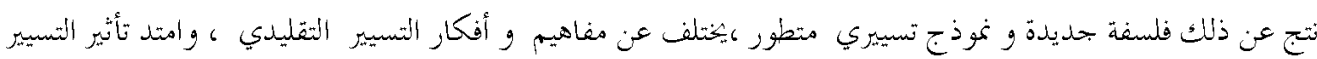

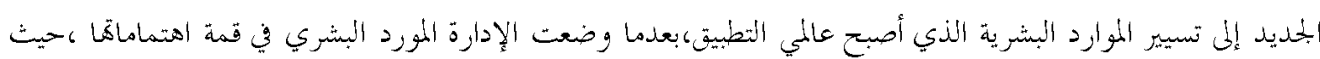

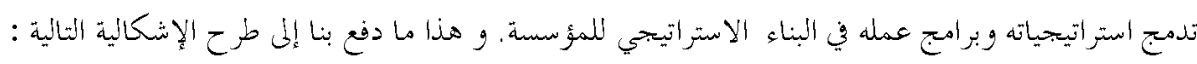

ما مدى تأثير العولمة على تسيير الموارد البشرية في المؤسسة الاقتصادية ؟

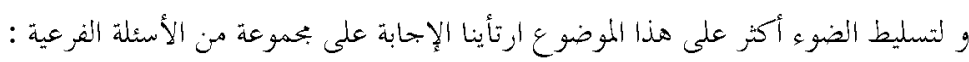

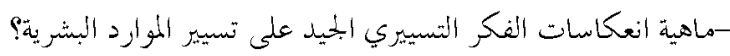

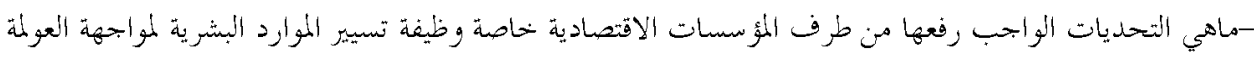
ذلك ما سوف نتعرض إليه في العناصر الآتية :

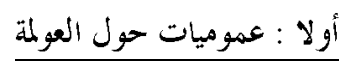

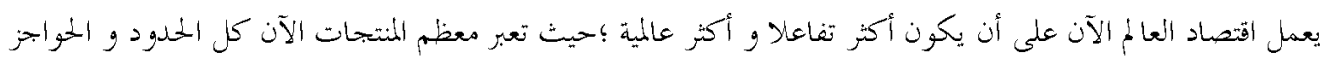

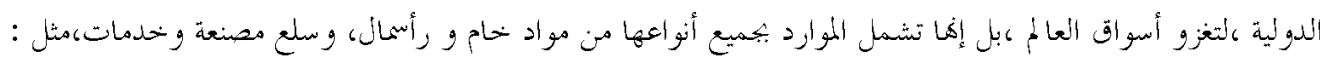
التأمين،وأنظمة الاتصال والأفراد. > >تعريف العوالمة : إن العولمة هي ترجمة لكمنتين 1: الآولى M ondialisation : بالفرنسية و الذي يقسمها إلى ثلاثة مصطلحات: Internationalisation: M ultinationalisationGlobalization-

${ }^{1}$ Fabienne Boudier, Mondialisation et Stratefie de firmes à l'international,2009 
أما الكلمة الثانية Globalization (المصطلح باللغة الإنجليزية ) و قد استعمل هذا اللفظ في أواخر القرن العشرين) و

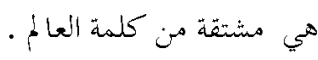
أما من الناحية اللغوية يقصد هما جعل المحلي عالميا، أي كل ما هو محلي أو وطني يصبح حاليا عالميا، فالعولمة هي إحدى

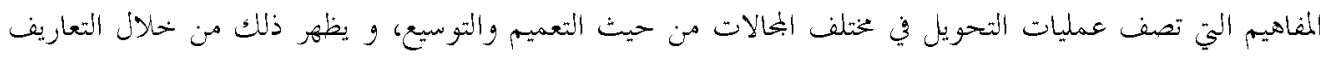
النالية

"تعريف صندوق النقد الدولي 》FMI «م حيث عرفها في تقريره " آفاق الاقتصاد العالم"سنة 1997 ": بأهنا ثزايد

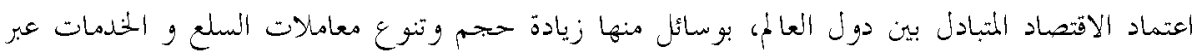

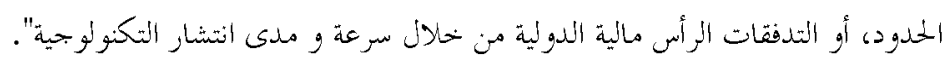

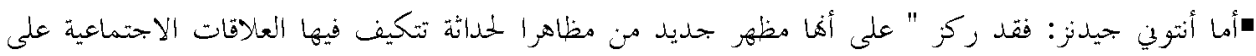

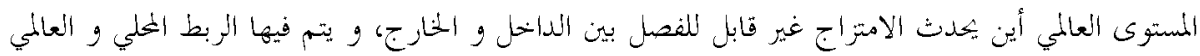
بروابط اقتصادية و ثقافية و سياسية و إنسانية".

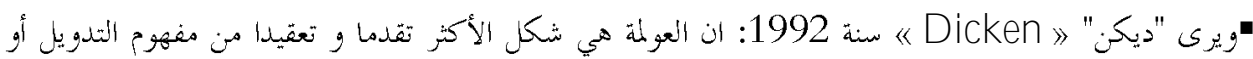

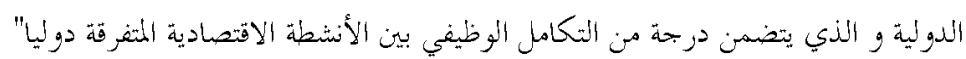

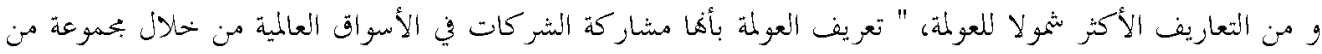

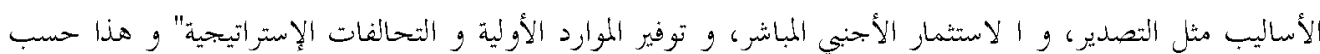
. 3 ereffi التطور التاريخي للعولمة

إن ظاهرة العولمة ليست بالجديدة لما جذور في التاريخ ، و قد مرت بمر حلتين أساسيتين:

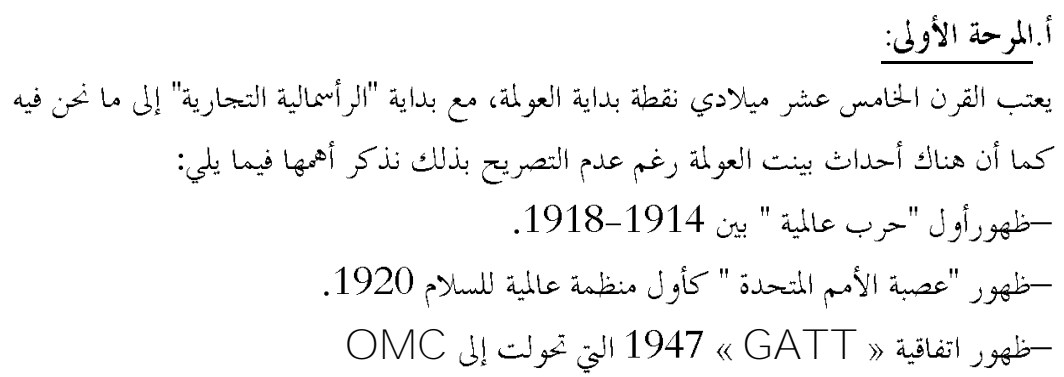

2د. عمر صقر ، "العولمة و قضايا اقتصادية معاصرة"، كلية التجارة و إدارة الأعمال، الطبعة 2003-2002

"The globalisation of markets, théodorelévite " :Havard business review maijuin 1993 repris par REM N ${ }^{\circ}=114$ 1987, aout, septembre - octobre 1987, lmenbéling global. 
Journal of Business \& Management (COES\&RJ-JBM), 4(2), pp. 61-71

$$
\text { بالماعلان العالمي "لحقوق الإنسان" ... إلخ. }
$$

كان لاتفاقية الخحات الأكبر الأثر الكبير في وضع قوانين جديدة تحكم العلاقات التجارية بين الدول، و في 1979 أدت

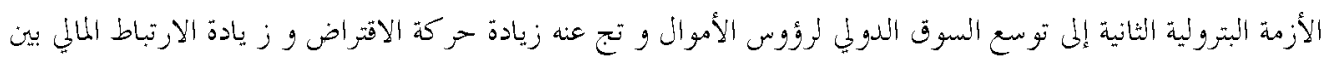

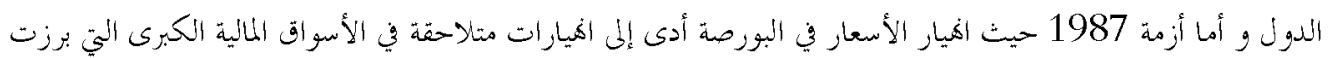

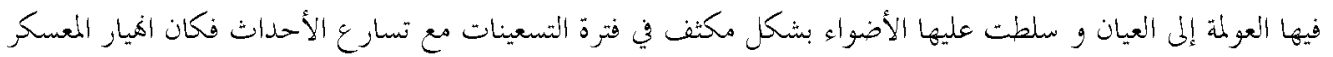

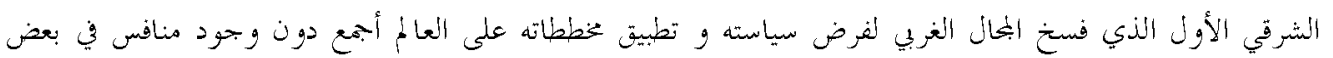

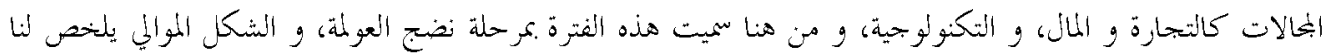

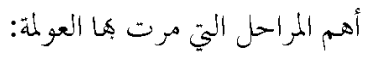

\section{: مراحل العولمة 1الشكل رقم :}

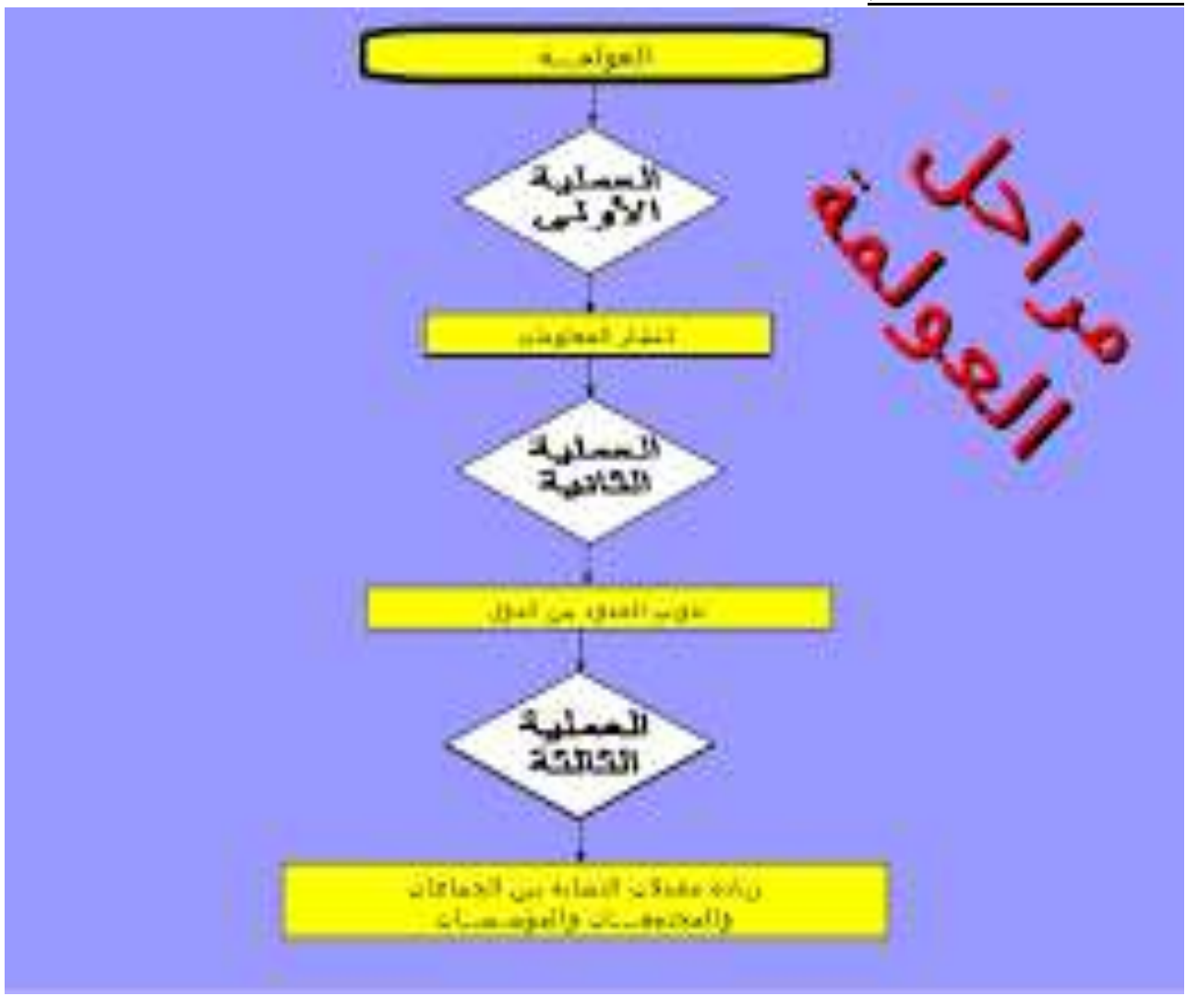

https://w w w.google.dz/search?: المصدر 


$$
\text { للعولمة أنواع بمكن تلخيصها فيما يلي: ألنواع العملة: }
$$

-العولمة السياسية: تبرز مظاهر العولمة السياسية في إخضاع الكل فئل في سياسة القوة و الهيمنة العظمى فالقوة الوحيدة

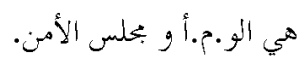

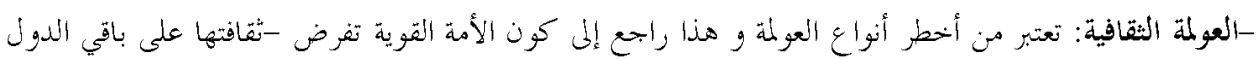

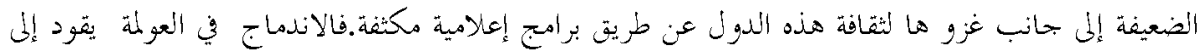

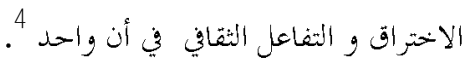

-العولمة الانصالية: و من مظاهرها البث التلفزيول بواسطة التقدم في الأقمار الصناعية، وشبكة الأنترنت و ما ينجم

$$
\begin{aligned}
& \text {-العوالمة العسكرية: و تعبن شل و إضعاف أية قوة إقليمية قد تبرز فيا لعالم من خلال العمل على تدميرها. } \\
& \text { - الكولمة المالية: ظهرت مع بداية التسعينات و من أهم مظاهرها: }
\end{aligned}
$$

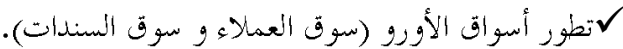

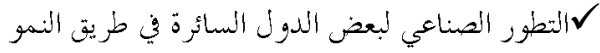

$$
\begin{aligned}
& \text { لاتوسع الاستثمارات الأجنبية و تدفق رؤوس الأموال. } \\
& \text { ل لطهور أدوات جديدة مثل العقود المستقبلية }
\end{aligned}
$$

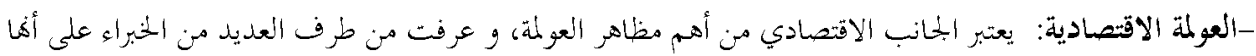

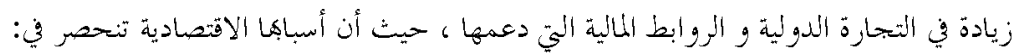

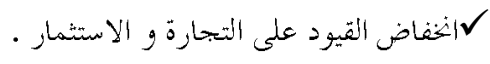

لالتطور الصناعي في الدول النامية و زيادة تكاملها مع الأسواق الاق العالمية.

لكامل أسواق المال فيما بينها.

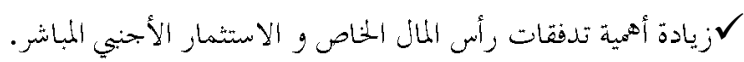

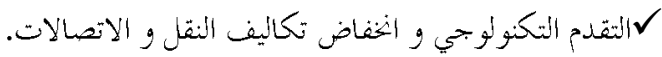

$$
\text { لاهيار الاتحاد السوفياتي }
$$

لأهور و توسع الشر كات المنعددة الجنسيات نو حدة المنافسة 6

ثانيا: التوجهات الجديدة للعولمة.

4 رعد سامي عبد الرزاق التميمي ، العولمة و التتمية البشرية المستدامة في الوطن العربي دار دجلة الطبعة الأولى ، 2000 ، ص56.

5ناجي مر اد، حاجي يوسف، "العولمة و التتمية الاقتصادية"، مذكرة ،كلية العلوم الاقتصادية و علوم التسيير - جامعة

تلمسان 2005-2006، ص بر 08.

6ناجي مر اد، حاجي يوسف، "العولمة و التتمية الاقتصـادية"، مرجع سابق ذكره، ص 09. 
العولمة هي التعبير الشامل عن الحالة الجحديدة الموجود عليها العالم اليوم،معتل كالتحولات و التغيرات، حيث أصبحت المؤسسات في يختلف دول العالم تسعى لاستثمار الفرص السانحة في سوق عالمية كبيزة.

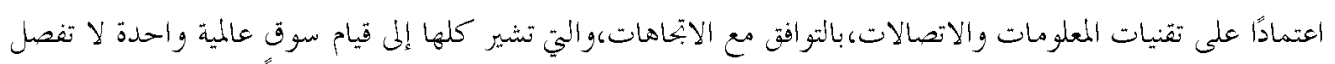

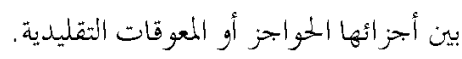

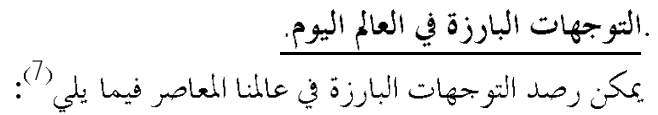

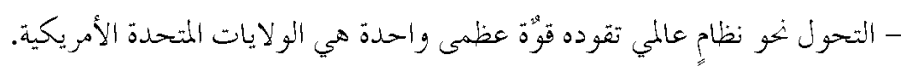
-التحول في معظم دول العالم نو اقتصاديات السوق.

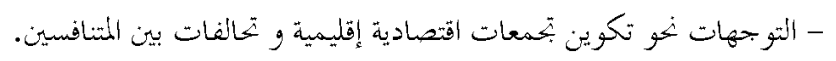
- الانطلاقة الهائلة للثورة التقنية و العلمية. - اشتخداد المنافسة العالمية.

\section{|| II العولمة والمؤسسات الإقتصادية.

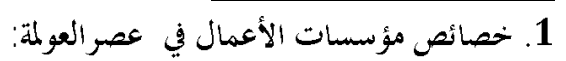

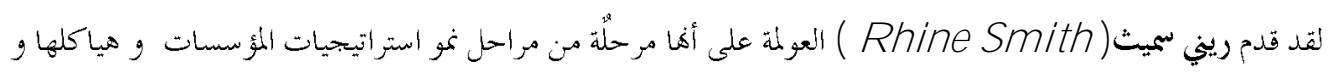
ثقافتها ،أي أهنا سلوك تنظيمي متطور تتبناه المؤ سسة ؛ همدف التفاعل مع جملة من العوامل المتشابكة.

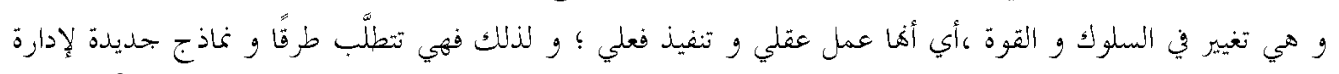

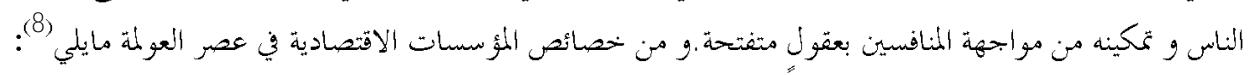

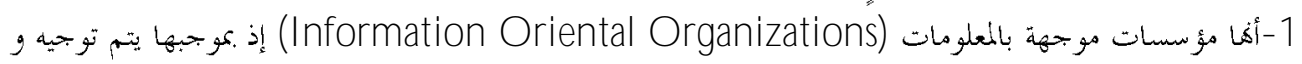
تسبير كل الأننشة و عمليات المؤمسة ، و ويتم التخاذ القرارات.

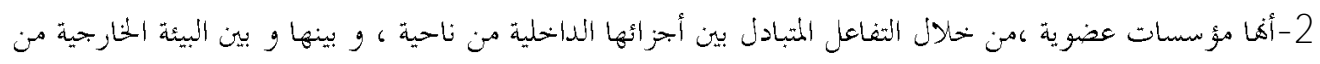
جهة أخرى.

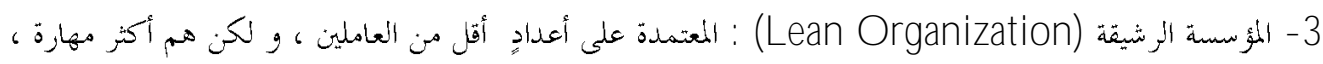

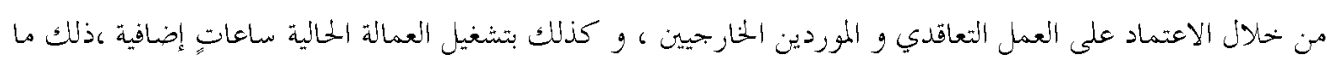

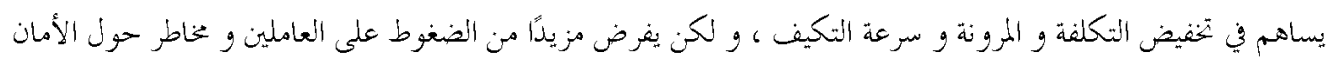
4 -زيادة درجة التعقدا، حيث ومن المتوقع أن تزداد درجة التنوع في السنوات القادمةبوذلك نتيجة عولمة أسواق العمل،

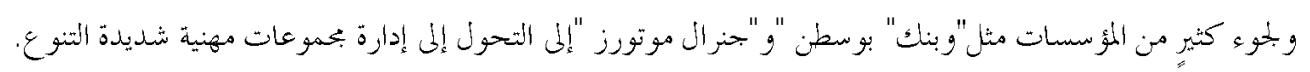

7- علي السلمي ،إدارة المو ارد البشرية الإستر اتيجية ، دار غريب،القاهرة، 2001 ،ص23 . 8- محمود أحمد الخطيب،إدارة الموارد البشرية، مكتبة عين الثمس، القاهرة 2001،ص 91 . 
5- التحول من الهياكل الرأسية التقليدية القائمة على تعلد مستويات السلطة، إلى الهياكل الأفقية التي تقوم على فرق

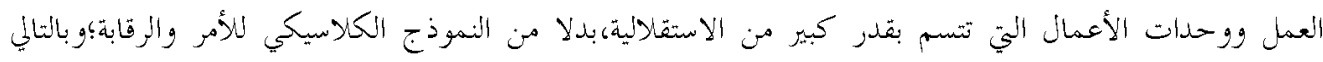

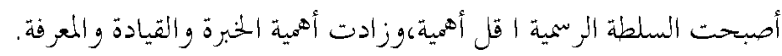

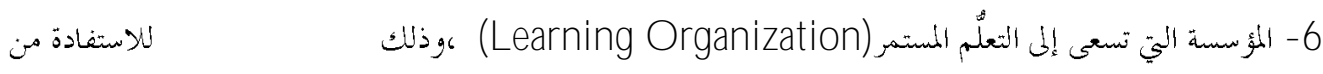

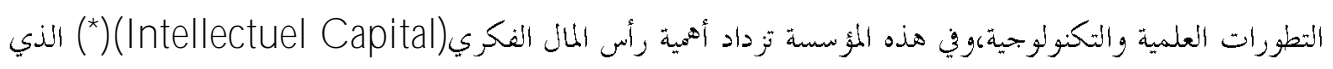

$$
\text { لصعين المعرفة التي يمكن توظيفها }
$$

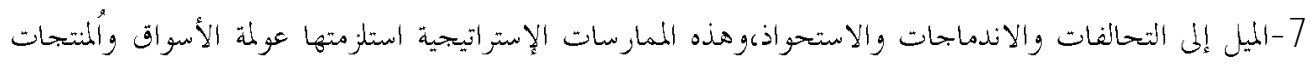

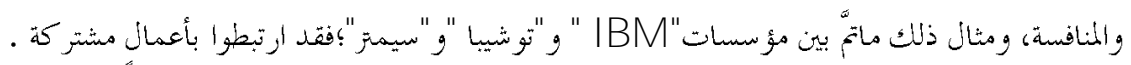

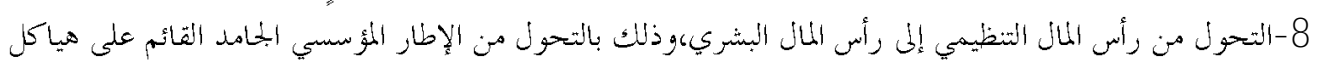
ووظائف ومستو يات ودرجات، إلى إطار معري ومهاري.

$$
\text { 1 1 1 1أثير العولمة على الموارد البشرية: }
$$

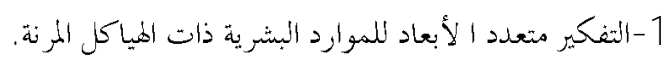

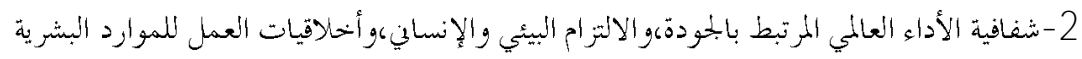

بالمؤسسات.

3 -التو سع في صناعة الخذدمات بجانب التكنولو جيات في أطر التنمية الاقتصادية و الاجتماعية.

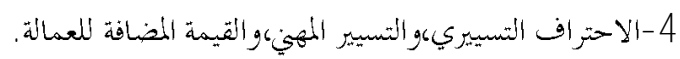

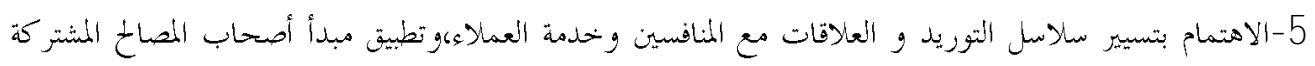

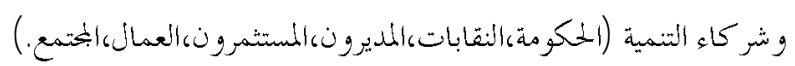

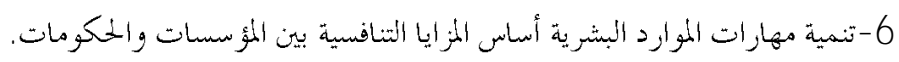

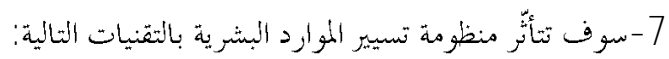

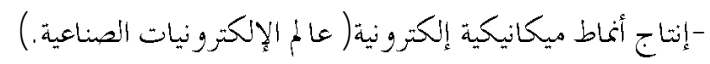

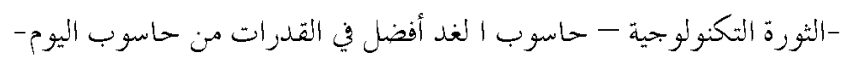

-تعاظم الاتصالات - المعلوماتية -والتحول إلى الاقتولية التصاد الرقمي.

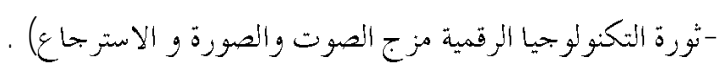

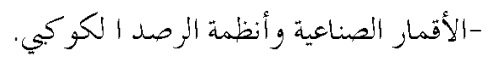

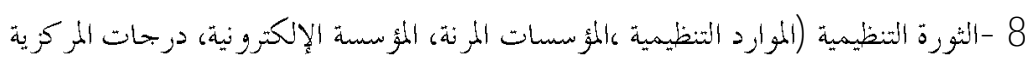

9- فريد النجار ، الإدارة الإستر اتيجية للموارد البشرية، الدار الجامعية، الإسكندرية، 2006، ص20. 
9 -معدل استعاب التكنولوجيا و حقوقا لملكية الفكرية و تأثير ذلك على هيكل الموارد البشرية .

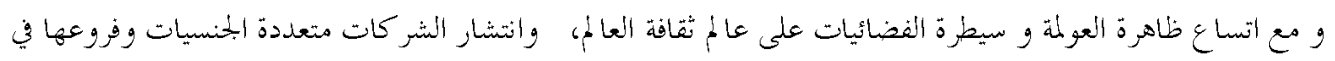

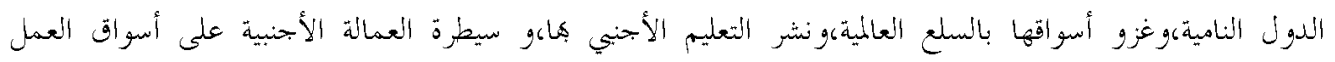

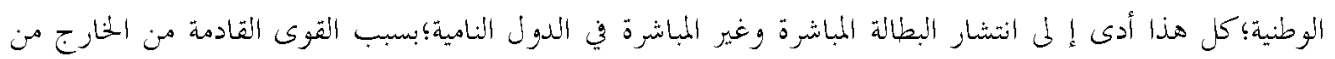

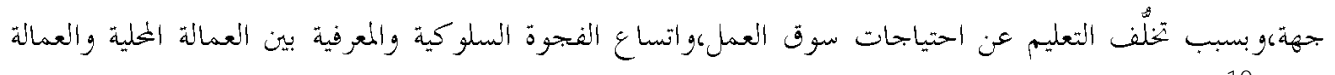

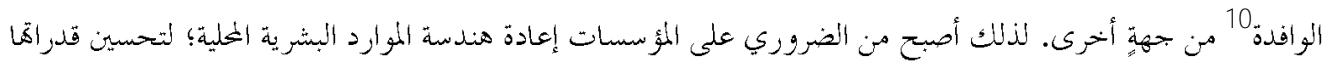

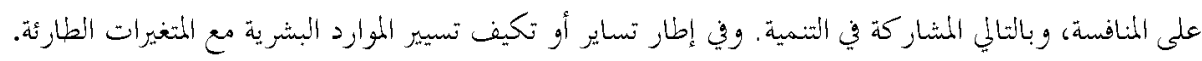

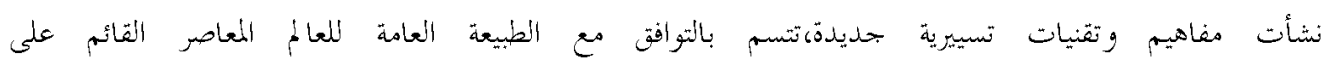

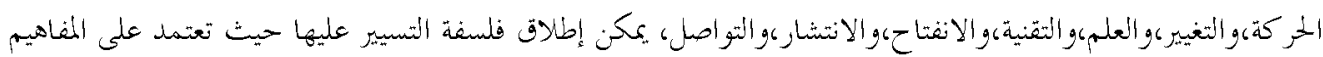

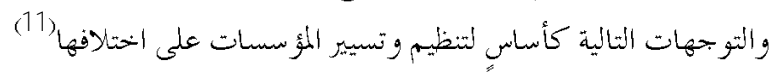
2-توجهات فلسفة الثسيير الجلديد:

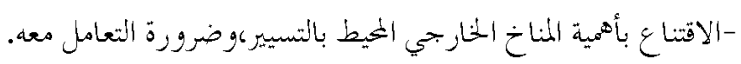

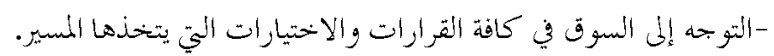

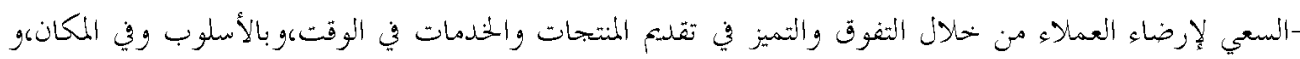

$$
\text { بالشروط التي يقبلوفنا. }
$$

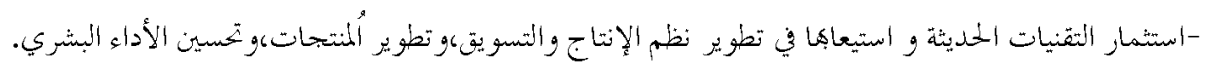

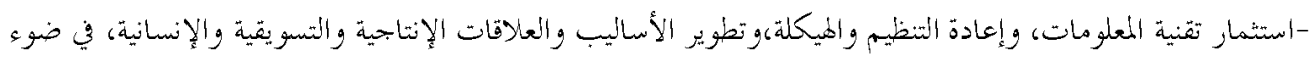

$$
\text { إمكانيات تقنية المعلومات. }
$$

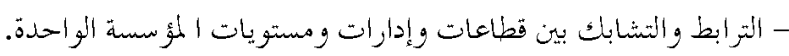
-تأكيد النظرة المستقبلية،و اعتناق التخطيط الاستراتيجي.

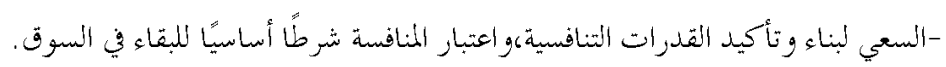

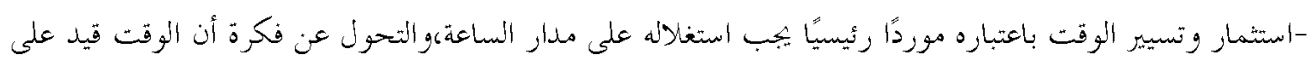
حر كة التسيبي.

\section{3- انعكاسات الفكر التسييري الجمديد على تسيير الموارد البثرية:}

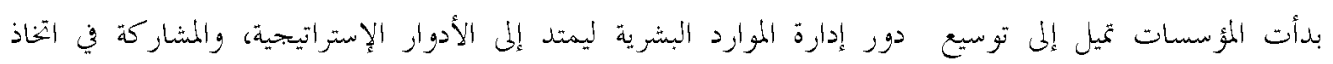

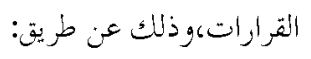

$$
10
$$

11- علي السلمي، إدارة المو ارد البشرية الإستر اتيجية، مرجع سابق، ص31. 
- تثغير النظرة إلى تسيير الموارد البشرية من كوها بحموعة أعمال إجرائية تتعلَّق بتنفيذ سياسات ونظم العاملين،إلى اعتبارها

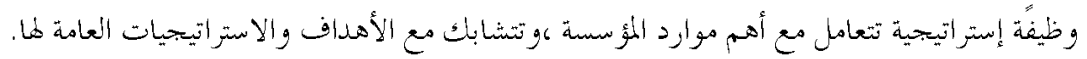

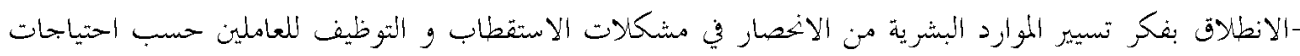

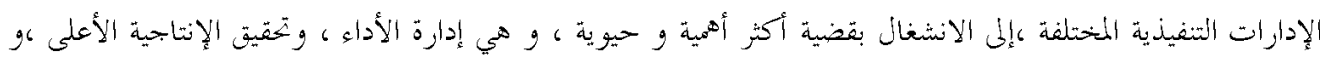
تحسين الكفاءة والفعالية. - تقابل وظيفة إدارة الموارد البشرية في كثير هن المؤسسات في مستواها مع إدارة الإنتاج و التسويق و التمويل بوهن هنا

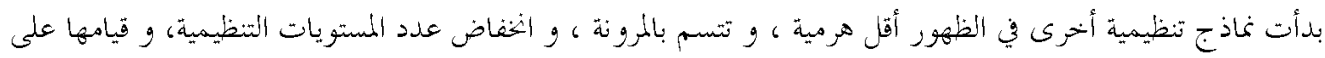

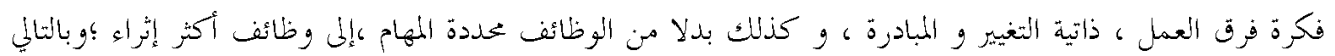

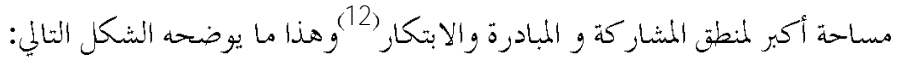
الشكل رقم 2

أن الأهمية النسبية للدور التنغيذي انخفضت من \% 60 إلى \% 10 بينما ازدادت الأهمية النسبية للدور الاستراتيجي

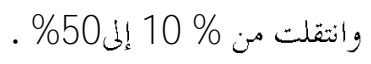
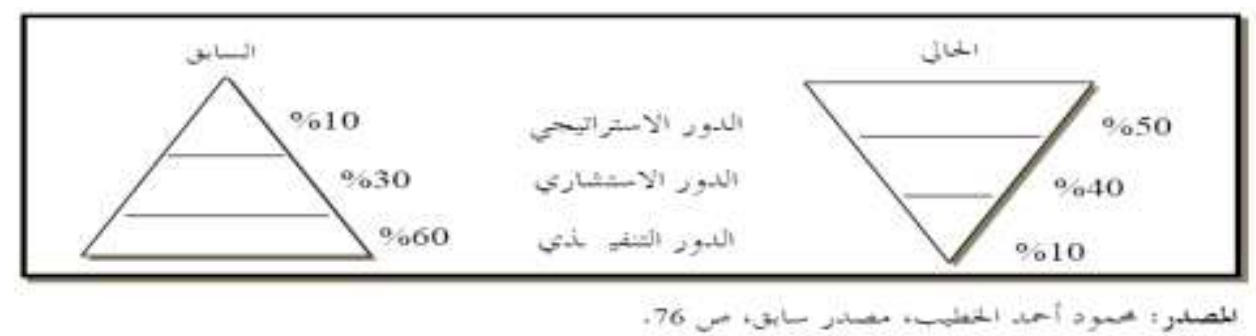

4-العولمة و التنافس و علاقتها بتسيير الموارد البشرية

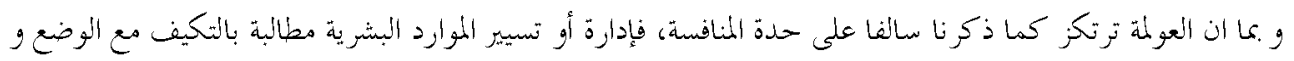

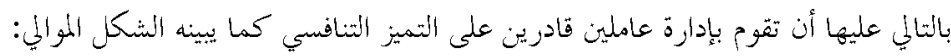

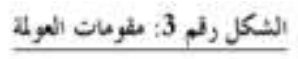

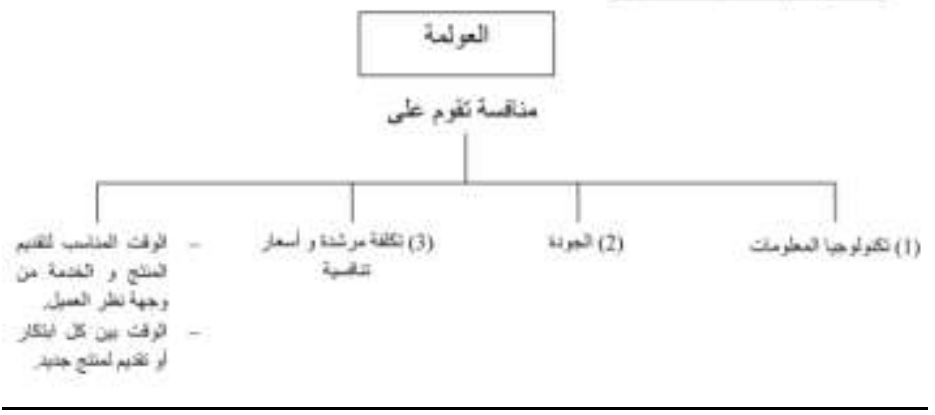

12- محمود أحمد الخطيب، مرجع سابق، ص75. 


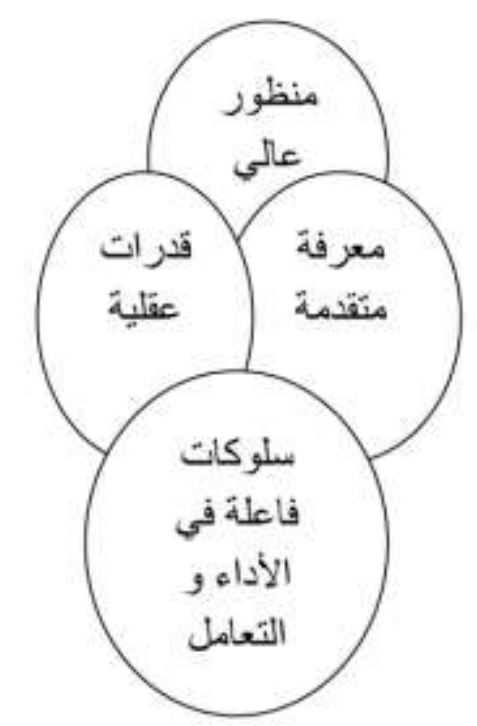

9......

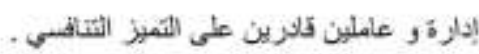

Intelligent \& Know gable people

من خلال :

المصدر: د. أحمد سيد مصطفى، "تحديات العولمة و التخطيط الاستر اتيجي"، جامعة الزفازيف، مصر،

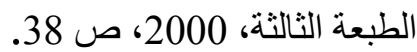
و من ثم، يمكن القول أن المؤسسات الاقتصادية، في ظل المنافسة الشديدة و الحادة المشتهودة مطالبة برفع تحديات على كل المستو يات:

5- 5 تحديات وظيفة تسيير الموارد البشرية في ظل العولمة:

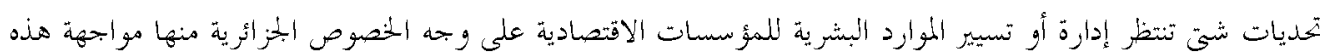

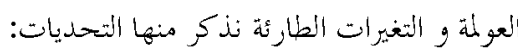

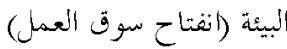
تحديات تمييز الأداء (تحسين أداء الأفراد، تنمية المهارات)

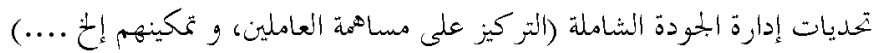

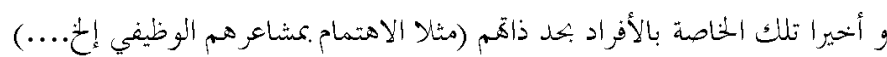

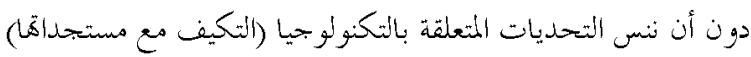

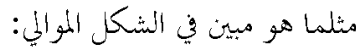




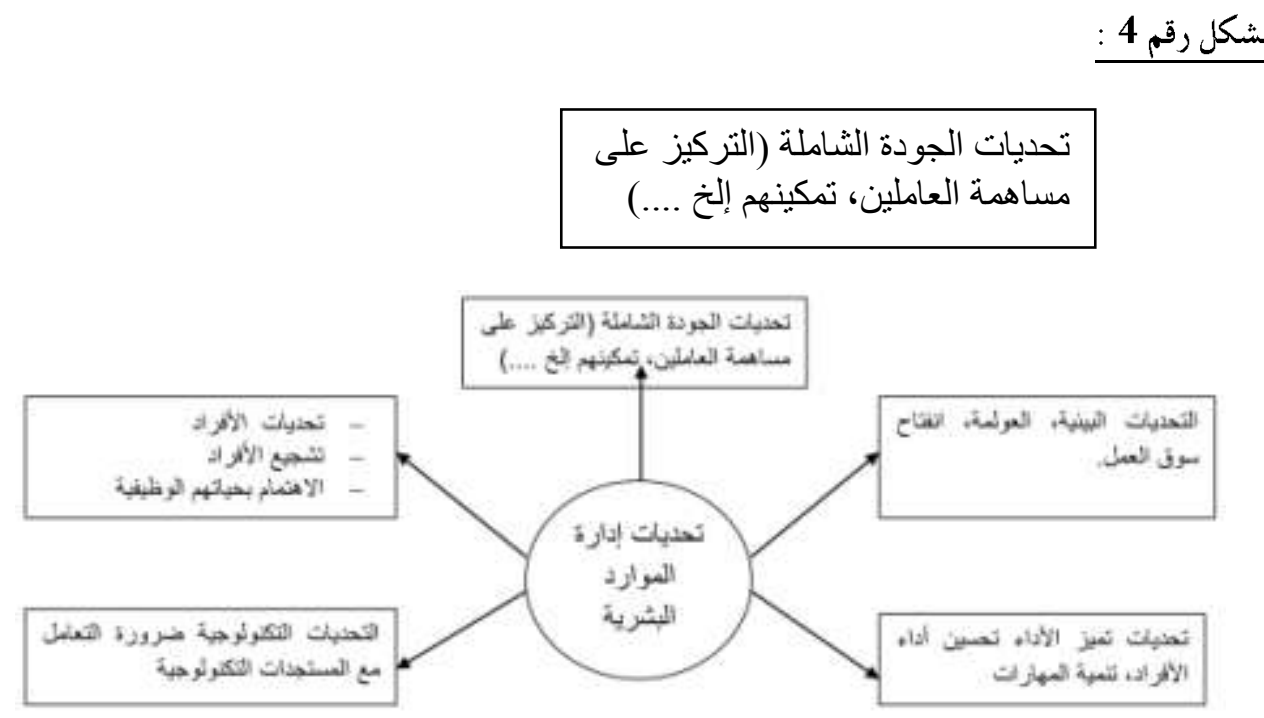

المصدر : و اقع تمكين العاملين بالمؤسسة الجز ائرية في ظل إدارة الجودة الثاملة سدر اسدة حالة : مؤسسة نفطال فرع GPL بثار ملياني زعيمة 2011-2012 ص بروسئ 66

\section{Bibliography:}

- Murad Naji, Yusuf Haji, "Globalization and economic development," the memorandum Bachelor, Tlemcen 2005-2006.

- Peaceful, strategic human resources, Dargrayb, Cairo 0.2001 management.

- Mahmoud Ahmed al-Khatib, human resources management, Ain Shams, Cairo 2001 Library,

- Fred Najjar, strategic management of human resources, University House, Alexandria, 2006, p. 20. 
- Omar Sakr, "Globalization and contemporary economic issues", Faculty of Commerce and Business Administration, 2002-2003 Edition,

- Fabienne Boudier» conférence "Mondialisation et Strategies de firmes à international" année 2009.

-The globalization of markets, Theodore Levite": Harvard business review maijuin 1993 repris par REM N ${ }^{\circ}=114$ 1987, Aout, septembre - octobre 1987, I menbéling global 